\title{
Análise de sensibilidade global dos parâmetros termofísicos de uma edificação residencial de acordo com o método de simulação do RTQ-R
}

\author{
Global sensitivity analysis of the physical parameters of a \\ residential building according to the RTQ-R simulation \\ method
}

\section{Arthur Santos Silva Enedir Ghisi}

\section{Resumo}

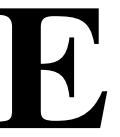

ste trabalho tem por objetivo analisar a sensibilidade global de parâmetros termofísicos considerados no Regulamento Técnico da Qualidade para o Nível de Eficiência Energética de Edificações Residenciais (RTQ-R). Um estudo de caso de uma habitação em Florianópolis, SC, foi realizado por meio de simulação computacional no EnergyPlus com o arquivo climático TRY. Foram definidos 15 parâmetros utilizados no RTQ-R, variados por meio de amostragem com o Hipercubo Latino e geraram-se 500 simulações aleatórias. As variáveis dependentes são os graus-hora de resfriamento, consumo relativo com aquecimento e com refrigeração. Para a análise de sensibilidade foram utilizados os métodos dos Coeficientes de Regressão Padronizados e Coeficientes de Correlação Parcial. Foram feitas análises de variabilidade e comparação de simulações individuais. Os resultados mostraram que os parâmetros mais influentes diferem para cada variável dependente, o que dificulta a proposta de soluções de desempenho que atendam às condições de verão e inverno simultaneamente. A absortância solar e a emissividade da cobertura foram os parâmetros mais influentes em geral. O trabalho contribuiu para a identificação quantitativa dos parâmetros mais influentes no desempenho da edificação, o que pode auxiliar nos processos de otimização e na proposta de níveis de classificação de desempenho em certificações.

Palavras-chave: Análise de sensibilidade global. Simulação de edifícios. Desempenho térmico. Eficiência energética. Edificação residencial.

Arthur Santos Silva Universidade Federal de Santa Catarina

Florianópolis - SC - Brasil

Enedir Ghis Universidade Federal de Santa Catarina Florianópolis - SC - Brasil

Recebido em 14/05/13 Aceito em 18/08/13

\begin{abstract}
This study aims to analyze the global sensitivity of the thermo-physical parameters considered in the Technical Quality Regulation for Energy Efficiency Level of Residential Buildings (RTQ-R). A case study of a house in Florianópolis, SC, was carried out through simulation on EnergyPlus, with the TRY weather file. Fifteen parameters used in the $R T Q-R$ were defined and varied using the Latin Hypercube Sampling, generating 500 random simulations. The dependent variables were the degree-hour for cooling, relative consumption with heating and with cooling. The sensitivity analysis was based on Standardised Regression Coefficients and Partial Correlation Coefficients. Variability analysis and comparison of individual simulations were performed. The results showed that the most influential parameters differ for each dependent variable, which hinders the proposal of performance solutions that meet summer and winter conditions simultaneously. The solar absorptance and the emissivity of the roof were the most influential parameters, in general. This study has contributed to identify quantitatively the most influential parameters in buildings, which may support performance optimization and proposals of performance rating levels on certifications.
\end{abstract}

Keywords: Global sensitivity analysis. Building simulation. Thermal performance. Energy efficiency. Residential building. 


\section{Introdução}

O uso de programas computacionais para modelagem térmica e energética de edificações se desenvolveu nos últimos anos juntamente com o aumento da capacidade de processamento dos computadores pessoais (RYAN; SANQUIST, 2012). Atualmente há 394 programas registrados para essa finalidade, de acordo com o Departamento de Energia dos Estados Unidos ${ }^{1}$.

Esses programas exigem grande quantidade de dados de entrada para a simulação (MENDES et al., 2005), muitas vezes indisponíveis ou de difícil obtenção.

No caso da eficiência energética de edificações, os programas de simulação computacional têm aplicação em diversos experimentos, tais como:

(a) processos de otimização de desempenho térmico e energético, possibilitando a verificação de inúmeras estratégias nos diversos sistemas da edificação (envoltória, iluminação, condicionamento de ar, aquecimento);

(b) calibração do modelo de simulação por meio de comparação com o consumo de energia medido em auditoria, de forma a propor soluções específicas para retrofit; e

(c) auxílio no processo de projeto de edificações eficientes, com base em normalizações ou certificações.

Grande parte das publicações a respeito da eficiência energética de edificações se baseia no princípio "E se", ou seja, analisam qual a variação da resposta do sistema se forem geradas perturbações nos parâmetros de entrada (HOPFE; HENSEN, 2011). Esse é o conceito-base da análise de sensibilidade.

Apesar de o princípio "E se" ser a forma de análise mais comum nessa área, poucas publicações promovem o aprimoramento desse método de avaliação, ou buscam formas mais completas de propor experimentos.

Há diversas formas de se promover uma análise "E se". Se o objetivo é determinar a influência dos parâmetros, há a análise de sensibilidade; se o objetivo é determinar uma função matemática ou computacional para representar uma amostra de dados, há as regressões lineares, não lineares e redes neurais; se o objetivo é determinar o intervalo de variação de um parâmetro de saída devido à variabilidade dos parâmetros de entrada, há a análise de incertezas, de variabilidade ou análise de riscos (KLEIJNEN, 1997).

\footnotetext{
${ }^{1}$ Dados disponíveis em: <http://apps1.eere.energy.gov>.
}

Sobre a análise de sensibilidade há, ao menos, três tipos encontrados na literatura (HEISELBERG et al., 2009; BREESCH; JANSSENS, 2010):

(a) análise por triagem;

(b) análise local; e

(c) análise global.

A análise por triagem contempla o método mais comum encontrado nas publicações (SALTELLI; TARANTOLA; CAMPOLONGO, 2000). Basicamente, os parâmetros de entrada são variados individualmente em dois níveis extremos, enquanto os demais parâmetros são mantidos no nível médio. Dessa forma, é obtida uma influência de primeira ordem, que pode ser útil para análises preliminares, mas é incompleta.

A análise local trata apenas de um parâmetro específico variado em diversos níveis, cujos demais parâmetros são mantidos constantes. Assim, obtém-se a tendência do parâmetro analisado em cada nível, podendo-se também variar os demais parâmetros, mas separadamente.

A análise global é a mais completa e complexa, pois se refere à variação de todos os parâmetros simultaneamente. Por meio dessa análise são obtidos índices globais de sensibilidade (SALTELLI; TARANTOLA; CAMPOLONGO, 2000).

Esse tipo de análise tem grande aplicação em normalizações de eficiência energética. No âmbito residencial, há o Regulamento Técnico da Qualidade para o Nível de Eficiência Energética de Edificações Residenciais (RTQ-R) (INSTITUTO..., 2012). O regulamento propõe dois métodos para a avaliação: o primeiro método (prescritivo) aponta indiretamente índices de sensibilidade para os parâmetros, pois a determinação da eficiência se baseia em regressão linear multivariada; o segundo método (simulação) fixa alguns parâmetros e configurações para as análises, o que facilita a aplicação do método ao reduzir a incerteza no momento da construção do modelo computacional.

A análise de sensibilidade é uma investigação sistemática da resposta de uma simulação quanto aos valores extremos dos parâmetros quantitativos analisados ou quanto a mudanças drásticas nos parâmetros qualitativos (KLEIJNEN, 1997).

Recentemente, Tian (2013) realizou uma revisão bibliográfica de métodos de análise de sensibilidade no desempenho energético de edificações. O autor apresenta os métodos mais comuns de análise de sensibilidade e propõe uma 
divisão em apenas dois tipos, (1) análise local e (2) análise global, diferentemente de outros autores, que acrescentam um terceiro tópico separadamente, a análise por triagem (HEISELBERG et al., 2009).

Entre outras contribuições em seu estudo, Tian (2013) apresenta as dificuldades que podem ser encontradas nesses experimentos, como a definição das variáveis analisadas, de sua distribuição de probabilidades, e escolher o método ideal lidando com o esforço computacional, o tempo de simulação e a precisão necessária do experimento.

Tian (2013) aponta que, quanto mais um programa de simulação foca apenas nos aspectos de design e em interfaces para usuários, mais difícil é a implementação de análise de sensibilidade, pois o próprio método necessita de rotinas automatizadas para a geração de diversas simulações.

Hopfe e Hensen (2011) analisaram a incerteza de parâmetros relacionados ao desempenho energético de edificações visando ao auxílio no processo de projeto. A análise de incertezas tem a especificidade de adotar pequenas variações nos parâmetros de entrada, de forma a analisar seus efeitos combinados na variável de saída. Os autores aplicaram o método Coeficientes de Correlação Ordenados Padronizados (SRRC, em inglês) para determinar quais parâmetros apresentam as incertezas mais influentes na variabilidade do consumo de energia com aquecimento e refrigeração da edificação, por simulação computacional no programa VA114 ${ }^{2}$. O clima analisado é o da Holanda. Os parâmetros físicos mais influentes foram as taxas de infiltração de ar (tanto no aquecimento quanto na refrigeração), a condutividade térmica de um dos materiais do piso e a espessura de um dos materiais da cobertura, para o aquecimento.

Yildiz e Arsan (2011) analisaram parâmetros de uma edificação residencial multifamiliar em IzmirTurquia (clima quente e úmido) que influenciam nas cargas de aquecimento e refrigeração pelo programa EnergyPlus. Os parâmetros foram variados conforme distribuição uniforme contínua, em intervalo de $95 \%$ de confiabilidade, e são relacionados às propriedades térmicas dos materiais, ao comportamento do usuário e à arquitetura dos ambientes. Para a amostragem foi utilizado o Hipercubo Latino, e para a análise de sensibilidade, o Coeficiente de Regressão Ordenado Padronizado. Entre os resultados, podese citar que a ordem dos parâmetros mais influentes não foi diferente entre os pavimentos

${ }^{2}$ Disponível em: <www.vabi.nl>. (térreo, tipo e o pavimento da cobertura), mas que podem, sim, ser diferentes dependendo da edificação; a orientação solar foi muito influente; a infiltração de ar mostrou influência grande tanto no caso do aquecimento quanto da refrigeração. Outros parâmetros como as temperaturas de setpoint do sistema de condicionamento de ar, propriedades térmicas dos vidros e a forma da edificação também foram influentes.

Hyun, Park e Augenbroe (2007) analisaram parâmetros que influenciam nas taxas de ventilação natural e na concentração de $\mathrm{CO}_{2} \mathrm{em}$ uma edificação residencial multifamiliar por meio de análise de sensibilidade com o programa CONTAMW 2.4 $4^{3}$. Os parâmetros mais influentes encontrados com o método de Morris (1991) foram a velocidade do vento, o fator de abertura das janelas determinado pelos ocupantes, constante de terreno, expoente de fluxo de ar e coeficiente de descarga.

Sorgato e Lamberts (2012) analisaram a influência de parâmetros relacionados ao cálculo da ventilação natural em uma edificação residencial unifamiliar: coeficientes de pressão, coeficientes de descarga, coeficientes de fluxo de ar por frestas e coeficiente de rugosidade do entorno. Foi utilizado o design fatorial para a análise, verificando-se a diferença percentual entre os casos. Entre esses quatro parâmetros analisados, a rugosidade do entorno apresentou a maior influência na taxa de renovação do ar por hora e nos graus-hora de resfriamento. A escolha errada do valor desses parâmetros pode comprometer significativamente os resultados das simulações.

Mara e Tarantola (2008) realizaram um estudo de calibração de uma célula teste por meio de análise de sensibilidade. Os autores utilizaram métodos baseados na análise de variância (ANOVA) para encontrar a sensibilidade e os efeitos de segunda ordem de 35 parâmetros em dez variáveis dependentes, inclusive a temperatura do ar. Utilizaram o método de Sobol' (1993) para modelos não lineares e verificaram que a absortância solar das superfícies externas foi a mais influente nas variáveis dependentes analisadas, assim como o albedo e um dos coeficientes de convecção de superfícies a sotavento.

Van der Knaap (2011) analisou a sensibilidade global dos parâmetros utilizados no RTQ-R pelo método prescritivo e por simulação computacional no EnergyPlus com o objetivo de comparar a diferença entre esses métodos. Por meio do Spearman Coefficients e com amostragem pelo

${ }^{3}$ Disponível em:

<http://www.bfrl.nist.gov/IAQanalysis/CONTAM/>. 
Hipercubo Latino, foi constatado que o método simplificado apresentou alta influência para a capacidade térmica do envelope, enquanto a simulação apresentou outros parâmetros mais influentes. Também verificou que o método simplificado subestima a eficiência da ventilação natural ao superestimar os graus-hora de resfriamento e o consumo com aquecimento.

Não foram encontrados estudos brasileiros que tratam de aplicação de métodos de análise de sensibilidade globais para a determinação da eficiência energética de edificações. Esses métodos propõem uma nova abordagem, possibilitando uma análise mais completa de cada caso, sem as limitações e as desvantagens dos métodos mais utilizados atualmente. Portanto, o objetivo deste trabalho é determinar a influência dos parâmetros termofísicos do RTQ-R por meio de análise de sensibilidade global na eficiência energética de uma edificação residencial por simulação computacional.

\section{Método}

O estudo tem como foco os parâmetros de entrada do RTQ-R (INSTITUTO..., 2012). Os parâmetros (variáveis independentes) foram definidos conforme o método prescritivo do RTQ-R, enquanto as configurações das simulações computacionais e as variáveis dependentes foram definidas conforme o método de simulação do referido regulamento.

Primeiramente, foi feita a definição do estudo de caso e foi determinada a tipologia da edificação. Em seguida, foram definidos os parâmetros e feita a amostragem aleatória, para, no fim, realizar o tratamento de dados, que consiste na análise de sensibilidade e variabilidade das variáveis dependentes.

\section{Definição do estudo de caso}

Para a análise foi adotada uma tipologia de edificação residencial unifamiliar que possui três dormitórios, sala e cozinha conjugadas e banheiro, conforme apresentado na Figura 1. A tipologia foi mantida fixa para os fins deste trabalho, e outras tipologias poderiam ser utilizadas e apontar diferentes resultados.

Foi utilizado o programa EnergyPlus versão 7.2 para a realização das simulações. Foi utilizado o arquivo climático TRY de Florianópolis, SC, obtido por Goulart, Lamberts e Firmino (1998).

As configurações de cargas internas, padrões de uso e ocupação, ventilação natural e sistema de condicionamento de ar foram definidas conforme o método de simulação do RTQ-R (INSTITUTO..., 2012).

O número de habitantes foi fixado em dois por dormitório, totalizando seis habitantes na sala/cozinha, enquanto a taxa de metabolismo foi de $81 \mathrm{~W} /$ pessoa nos dormitórios e $108 \mathrm{~W} /$ pessoa na sala/cozinha.

A densidade de potência instalada com iluminação é de $6 \mathrm{~W} / \mathrm{m}^{2}$ na sala/cozinha e de $5 \mathrm{~W} / \mathrm{m}^{2}$ nos dormitórios. A densidade de potência instalada com equipamentos é de $1,5 \mathrm{~W} / \mathrm{m}^{2}$ para os ambientes de permanência prolongada. A Figura 2 apresenta as rotinas de ocupação.

As rotinas de uso de equipamentos foram caracterizadas por uma fração constante de $100 \%$. As rotinas de uso da iluminação foram diferentes para cada ambiente e separadas por dia da semana ou fim de semana.

Para o cálculo da temperatura do solo foi utilizado o programa Slab, vinculado ao EnergyPlus.

\section{Figura 1 - Tipologia de edificação residencial analisada}

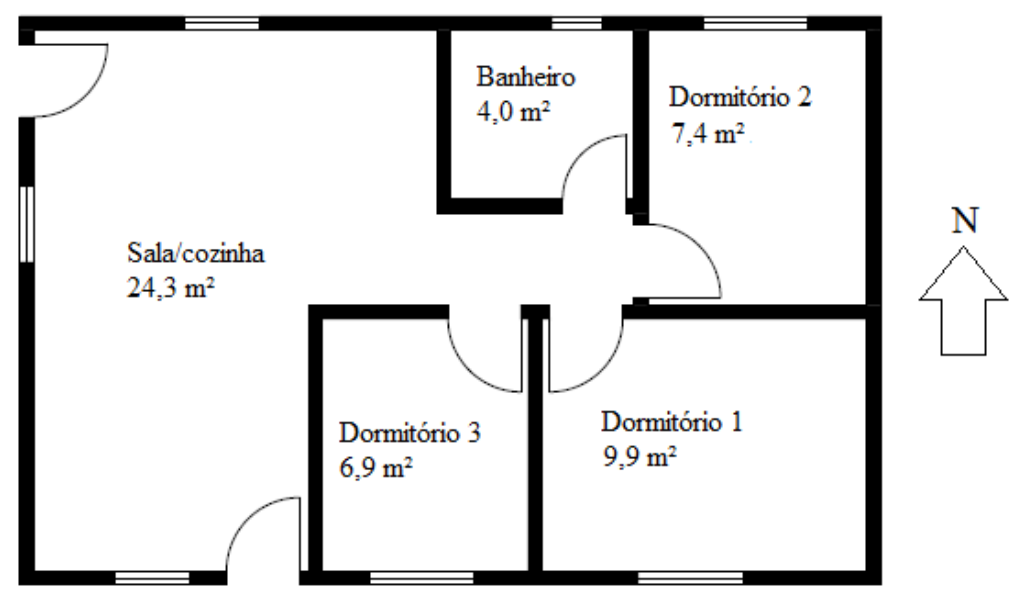

138 Silva, A. S.; Ghisi, E. 
Figura 2 - Rotinas de ocupação adotadas conforme o RTQ-R

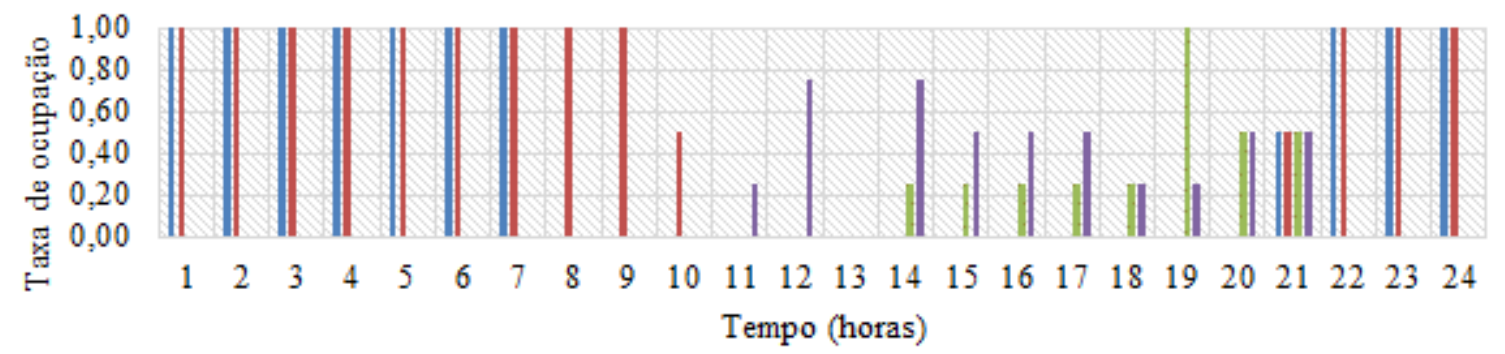

\author{
U ocupação dos dormitórios nos dias de semana I ocupação dos dorm itórios no fím de semana \\ " ocupação da sala nos dias de sem ana \\ - ocupação da sala no fim de sem ana
}

\section{Variáveis dependentes}

O RTQ-R apresenta três variáveis dependentes a serem obtidas com as simulações: graus-hora de resfriamento (GHR); consumo relativo com aquecimento (CA); e consumo relativo com refrigeração $(\mathrm{CR})$.

De acordo com o regulamento (INSTITUTO..., 2012), para a obtenção dessas variáveis é necessária a criação de dois modelos-base de simulação, sendo (1) naturalmente ventilado durante todo o ano e (2) naturalmente ventilado durante $\mathrm{o}$ dia $\mathrm{e}$ artificialmente condicionado durante a noite. A variável GHR é obtida a partir do modelo-base (1), com a Equação 1, e as variáveis CA e CR são obtidas a partir do modelobase (2), com as Equações 2 e 3.

$$
\begin{array}{lr}
\text { GHR }=\left\{\begin{array}{lr}
\text { se } T_{i}>26^{\circ} \mathrm{C}, & \sum_{i=0}^{8760} T_{i}-26^{\circ} \mathrm{C} \\
\text { se } T_{i} \leq 26^{\circ} \mathrm{C}, & \text { Eq. } 1
\end{array}\right. \\
C R=\frac{\sum_{i=0}^{8760} \mathrm{Cr} r_{i}}{A U} & \text { Eq. } 2 \\
C A=\frac{\sum_{i=0}^{8760} \mathrm{Ca} a_{i}}{A U} & \text { Eq. } 3
\end{array}
$$

Onde:

GHR são os graus-hora de resfriamento de cada ambiente de permanência prolongada $\left({ }^{\circ} \mathrm{Ch}\right)$;

$T_{i}$ são as temperaturas operativas horárias de cada ambiente de permanência prolongada $\left({ }^{\circ} \mathrm{C}\right)$;

$C r_{i}$ é o consumo de energia com refrigeração noturna horário de cada ambiente de permanência prolongada $(\mathrm{kWh})$;

$C a_{i}$ é o consumo de energia com aquecimento noturno horário de cada ambiente de permanência prolongada $(\mathrm{kWh})$;

$C R$ é o consumo relativo de energia com refrigeração noturna anual de cada ambiente dos dormitórios ( $\mathrm{kWh} / \mathrm{m}^{2}$.ano);
$C A$ é o consumo relativo de energia com aquecimento noturno anual de cada ambiente de permanência prolongada $\left(\mathrm{kWh} / \mathrm{m}^{2}\right.$.ano); e

$i$ é cada uma das 8760 horas do ano (hora).

Para o modelo-base (1), a ventilação natural está disponível o ano inteiro, com setpoint de temperatura de operação de $20^{\circ} \mathrm{C}$.

Para o modelo-base (2) foi definida ventilação natural diurna e condicionamento artificial noturno das $21 \mathrm{~h}$ às $8 \mathrm{~h}$. O sistema de aquecimento tem COP de $2,75 \mathrm{~W} / \mathrm{W}$, e o sistema de refrigeração tem COP de $3,00 \mathrm{~W} / \mathrm{W}$. A taxa de fluxo de ar por pessoa é de $0,00944 \mathrm{~m}^{3} / \mathrm{s}$, eficiência do motor de 0,90 e do ventilador de 0,70 .

De forma a se ter um indicador global da edificação, foram definidas mais três variáveis:

(a) GHR médio: média ponderada dos graus-hora de resfriamento de cada ambiente pela área útil;

(b) CA médio: soma dos consumos de energia com aquecimento de cada ambiente dividida pela área útil total dos ambientes aquecidos; e

(c) CR médio: soma dos consumos de energia com refrigeração de cada ambiente dividido pela área útil total dos ambientes refrigerados.

\section{Variáveis independentes}

Os parâmetros termofísicos da edificação são as variáveis independentes, determinados com base no método prescritivo do RTQ-R relacionados às propriedades térmicas do envelope, às propriedades das aberturas e ao contato das superfícies com o exterior. A Tabela 1 resume todos os 15 parâmetros termofísicos considerados e suas variações.

Diversos autores comentam sobre a falta de dados precisos da variabilidade dos parâmetros (HYUN; PARK; AUGENBROE, 2007; TIAN, 2013) e recomendam a adoção de distribuição normal na falta de dados precisos, enquanto Mechri, 
Capozzoli e Corrado (2010) recomendam a adoção de distribuição uniforme. Essa questão ainda não está clara na literatura, e mais estudos devem ser realizados para verificar se realmente os resultados seriam diferentes se fossem adotadas outras distribuições de probabilidades.

Tendo em vista que cada parâmetro tem suas peculiaridades, não foi adotada uma distribuição única para todos os parâmetros. A Figura 3 mostra as distribuições de probabilidades utilizadas neste trabalho. Os parâmetros de absortância solar da cobertura e de absortância solar das paredes externas e o fator de ventilação das aberturas foram considerados como distribuição triangular (Figura 3b). A mesma é uma distribuição contínua, onde são definidos os coeficientes $\alpha, \beta$ e $\gamma$, que delimitam o "triângulo". Todos os demais parâmetros da Tabela 1 são variados como distribuição discreta (como exemplifica a Figura 3a).
De forma a evitar o truncamento dos dados, a distribuição triangular foi escolhida como uma alternativa à distribuição normal, pois ela continua mantendo diferentes probabilidades de ocorrência para os valores, de forma simétrica e com maior probabilidade de ocorrência em torno da média.

Sobre a variável "cob", o nível 0 significa que a cobertura não transfere calor, e 1 significa que possui contato com o exterior. Para a variável "piso", o nível 1 significa que o piso está em contato com o solo, o nível 0,5 significa que está em contato com o exterior, por meio de pilotis, e o nível 0 significa que não transfere calor.

A orientação solar foi variada girando o azimute da Figura 1 de $90^{\circ}$ em $90^{\circ}$, totalizando quatro casos. Para o parâmetro "Somb" o nível 0 significa que não há veneziana, e o nível 1 significa que há.

Para os demais parâmetros térmicos procurou-se definir intervalos que fossem extremos e que representassem os componentes construtivos com possibilidade de ocorrência em edificações reais.

Figura 3 - Distribuições de probabilidades utilizadas no trabalho
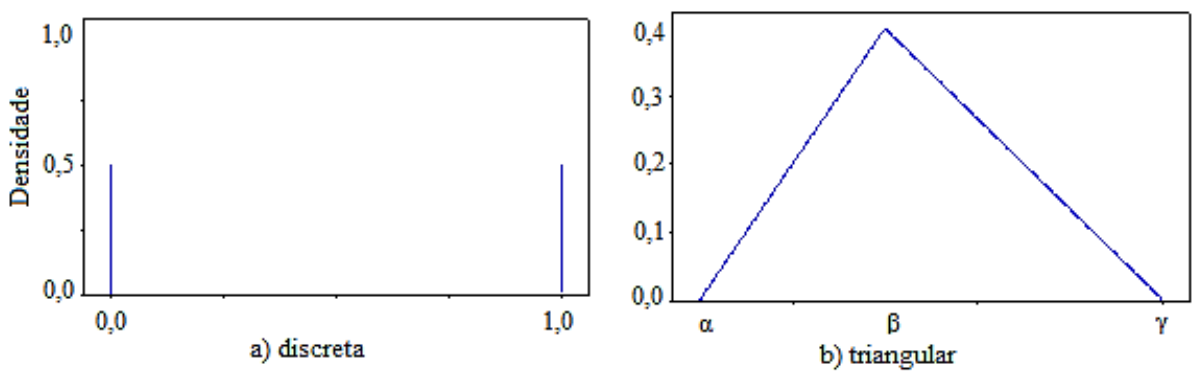

Tabela 1 - Variáveis independentes usadas nas simulações

\begin{tabular}{|c|c|c|c|c|}
\hline Parâmetro & ID & Unidade & Valor & Probabilidade \\
\hline Transmitância térmica da cobertura & Ucob & $\mathrm{W} / \mathrm{m}^{2} . \mathrm{K}$ & $1,00 / 2,50 / 4,00$ & $0,20 / 0,60 / 0,20$ \\
\hline Capacidade térmica da cobertura & CTcob & $\mathrm{kJ} / \mathrm{m}^{2} . \mathrm{K}$ & $20,0 / 110,0 / 200,0$ & $0,20 / 0,60 / 0,20$ \\
\hline Absortância solar da cobertura* & $\alpha \operatorname{cob}$ & adimensional & $0,10 / 0,50 / 0,90$ & variável \\
\hline Emissividade a ondas longas da cobertura & $\varepsilon c o b$ & adimensional & $0,10 / 0,90$ & $0,25 / 0,75$ \\
\hline Transmitância térmica das paredes externas & Uparext & $\mathrm{W} / \mathrm{m}^{2} \cdot \mathrm{K}$ & $1,00 / 2,35 / 3,70$ & $0,20 / 0,60 / 0,20$ \\
\hline Capacidade térmica das paredes externas & CTparext & $\mathrm{kJ} / \mathrm{m}^{2} \cdot \mathrm{K}$ & $49,9 / 150,0 / 250,1$ & $0,20 / 0,60 / 0,20$ \\
\hline Transmitância térmica das paredes internas & Uparint & $\mathrm{W} / \mathrm{m}^{2} . \mathrm{K}$ & $1,00 / 2,35 / 3,70$ & $0,20 / 0,60 / 0,20$ \\
\hline Capacidade térmica das paredes internas & CTparint & $\mathrm{kJ} / \mathrm{m}^{2} \cdot \mathrm{K}$ & $49,9 / 150,0 / 250,1$ & $0,20 / 0,60 / 0,20$ \\
\hline Absortância solar das paredes externas* & apar & adimensional & $0,10 / 0,50 / 0,90$ & variável \\
\hline Contato da cobertura com o exterior & $\mathrm{cob}$ & adimensional & $0 / 1$ & $0,20 / 0,80$ \\
\hline Contato do piso com o exterior ou com o solo & piso & adimensional & $0,0 / 0,5 / 1,0$ & $0,15 / 0,15 / 0,70$ \\
\hline Fator de ventilação das aberturas* & Fvent & adimensional & $0,45 / 0,50 / 0,90$ & variável \\
\hline Existência de veneziana nas aberturas & Somb & adimensional & $0 / 1$ & $0,80 / 0,20$ \\
\hline Orientação solar & Solar & graus & $0 / 90 / 180 / 270$ & $0,25 / 0,25 / 0,25 / 0,25$ \\
\hline Transmitância térmica dos vidros & Uvid & $\mathrm{W} / \mathrm{m}^{2} . \mathrm{K}$ & $5,36 / 6,27$ & $0,10 / 0,90$ \\
\hline
\end{tabular}

Nota: *Parâmetros variados por meio de distribuição triangular, definidos a partir de um limite inferior, uma média e um limite superior. Os demais parâmetros foram definidos como distribuição discreta. 
O único parâmetro incluído neste trabalho que não é considerado no RTQ-R é a emissividade da cobertura, variada em 0,10 e 0,90 para representar emissividade baixa (superfícies condutoras elétricas - metais) ou alta (demais tipos de superfícies), respectivamente.

Como a transmitância e a capacidade térmica têm a peculiaridade de ser variáveis discretas, outra abordagem foi necessária como alternativa às distribuições contínuas. Por isso, foram definidas variáveis discretas com probabilidades de ocorrência diferenciadas para cada nível. No caso das transmitâncias e capacidades térmicas, o valor médio tem $60 \%$ de probabilidade de ocorrência, enquanto os extremos têm $20 \%$. Ressalta-se que as probabilidades adotadas visam manter uma tendência de $\mathrm{o}$ valor central ter maior probabilidade de ocorrência que os extremos, o que é fisicamente a realidade. Se fosse adotada a mesma probabilidade nos níveis, combinações muito discrepantes e que não aconteceriam na realidade poderiam ser geradas.

\section{Amostragem aleatória}

Para este trabalho foi utilizada a amostragem aleatória pelo Hipercubo Latino, o qual gera vetores aleatórios para cada uma das variáveis independentes, considerando a probabilidade de ocorrência em cada distribuição da Tabela 1.

Como o número de parâmetros não está diretamente associado ao número de simulações nesse método, foi adotado um vetor aleatório de tamanho 500, determinado com o programa SimLab 2.2. Alguns autores recomendam que o número de simulações seja maior do que 80 (MACDONALD; STRACHAN, 2001), outros recomendam que seja maior do que $3 / 2$ do número de parâmetros (BREESCH; JANSSENS, 2005). Em ambos os casos, o número escolhido neste trabalho é suficientemente satisfatório.

Outros métodos de amostragem poderiam ser aplicados, porém não seria adequado escolher um método de design fatorial, pois há 15 variáveis na Tabela 1, com 2, 3 ou 4 níveis de variação. Sendo assim, seriam necessárias mais de $3 \times 10^{6}$ simulações, inviabilizando este estudo. Além disso, o design fatorial deve ser feito para parâmetros estritamente discretos com dois níveis extremos de variação, e no caso deste trabalho foram considerados alguns com distribuição contínua.

A análise deste trabalho resultou em 500 simulações com o EnergyPlus para o modelo-base 1 (naturalmente ventilado) e 500 simulações para o modelo-base 2 (artificialmente condicionado).

\section{Tratamento de dados}

\section{Análise de sensibilidade}

Por ser escolhido um método de amostragem aleatória, não podem ser utilizados métodos baseados na análise de variância para analisar a sensibilidade. Sendo assim, foram escolhidos dois métodos de análise de sensibilidade, (1) os Coeficientes de Regressão Padronizados (SRC em inglês) e o (2) os Coeficientes de Correlação Parcial (PCC em inglês), calculados com o programa SimLab 2.2 (SIMLAB, 2013).

O SRC é baseado em regressão linear, conforme a Equação 4.

$y_{i}=b_{0}+\sum_{j} b_{j} x_{i j}+\varepsilon_{i}$

Eq. 4

Onde:

$y_{i}$ é o valor i de cada variável dependente y (GHR, $\mathrm{CA}$ ou $\mathrm{CR}$ ), com unidade variável em ${ }^{\circ} \mathrm{Ch}$ ou $\mathrm{kWh} / \mathrm{m}^{2}$.ano;

$b_{0}$ é uma constante da regressão (adimensional);

$\varepsilon_{i}$ é o erro (unidade variável);

$x_{i j}$ é o valor i de cada variável independente $\mathrm{j}$ (unidade variável); e

$b_{j}$ são os coeficientes de cada variável independente, determinados com o método dos mínimos quadrados (adimensional).

Assumindo-se que os coeficientes $b_{j}$ de cada regressão foram computados, parte-se para a normalização com as Equações 5 a 8 (SIMLAB, 2013).

$\frac{y-\bar{y}}{\hat{s}}=\sum_{j}^{k}\left(\frac{b_{j} \hat{s_{J}}}{\hat{s}}\right)\left(\frac{x_{j}-\bar{x}_{j}}{\widehat{s_{j}}}\right)$

$\hat{s}=\left[\sum_{i}^{N} \frac{\left(y_{i}-\bar{y}\right)^{2}}{(N-1)}\right]^{1 / 2} \quad$ e $\bar{y}=\frac{\sum_{i}^{N} y_{i}}{N}$

$\widehat{s_{J}}=\left[\sum_{i}^{N} \frac{\left(x_{i j}-\overline{x_{J}}\right)^{2}}{(N-1)}\right]^{1 / 2}$ e $\bar{x}_{j}=\frac{\sum_{i}^{N} x_{i j}}{N}$

$S R C_{j}=\frac{b_{j} \hat{s}_{j}}{\hat{s}}$

Onde:

$x$ são as variáveis independentes (unidade variável);

$y$ são as variáveis dependentes $\left({ }^{\circ} \mathrm{Ch}\right.$ ou $\mathrm{kWh} / \mathrm{m}^{2}$.ano);

$k$ é o número de variáveis independentes (adimensional);

$N$ é o tamanho da amostra (adimensional);

$i$ é cada valor individual da amostra (adimensional); 
$j$ é cada variável independente (adimensional);

$b_{j}$ são os coeficientes de regressão pelo método dos mínimos quadrados (adimensional); e

$S R C_{j}$ são os Coeficientes de Regressão

Padronizados de cada variável independente (adimensional).

O PCC é calculado com base em correlações completas e correlações parciais (SIMLAB, 2013), de acordo com as Equações 9 e 10. As correlações parciais são obtidas por meio de duas equações de regressão, conforme a Equação 11. Por meio delas, são obtidas novas variáveis $(Y-\hat{Y})$ e $(X-\hat{X})$. O PCC entre $X$ e $Y$ é definido como o coeficiente de correlação entre $(Y-\hat{Y})$ e $(X-\hat{X})$. Esse coeficiente representa a força de correlação linear entre essas duas variáveis, excluindo-se todos os efeitos das variáveis independentes entre si.

$r_{x j y}=\frac{\sum_{i=1}^{m}\left(x_{i j}-\bar{x}_{j}\right)\left(y_{i}-\bar{y}\right)}{\left[\sum_{i=1}^{m}\left(x_{i j}-\bar{x}_{j}\right)^{2}\right]^{1 / 2}\left[\sum_{i=1}^{m}\left(y_{i}-\bar{y}\right)^{2}\right]^{1 / 2}}$

$\bar{y}=\sum_{i}^{m} \frac{y_{i}}{m}$ e $\quad \overline{x_{j}}=\sum_{i}^{m} \frac{x_{i j}}{m}$

$\hat{Y}=b_{0}+\sum_{h \neq j}^{k} b_{h} x_{h}$ e $\hat{X}=c_{0}+\sum_{h \neq j}^{k} c_{h} x_{h}$ Eq. 11

Onde:

$r_{x j y}$ é a correlação entre $x$ e $y$ (adimensional);

$x$ são as variáveis independentes (unidade variável);

y são as variáveis dependentes $\left({ }^{\circ} \mathrm{Ch}\right.$ ou $\mathrm{kWh} / \mathrm{m}^{2}$.ano);

$m$ é o tamanho da amostra (adimensional);

$b_{0} e c_{0}$ são constantes da regressão (adimensional);

$b_{h} e c_{h}$ são os coeficientes de regressão pelo método dos mínimos quadrados (adimensional);

$\hat{Y}$ é a transformação de variável dependente (unidade variável); e

$\hat{X}$ é a transformação de variáveis independentes (unidade variável).

Para ambos os métodos, são calculados os coeficientes de determinação $\mathrm{R}^{2}$, que indicam a quantidade da variância que pode ser explicada pela regressão linear. Também se indica o quão confiável é análise de sensibilidade da amostra. O $\mathrm{R}^{\mathbf{2}}$ é calculado considerando-se uma regressão multivariada, ou seja, há apenas um valor de $\mathrm{R}^{2}$ para toda a amostra, e não um valor para cada parâmetro.

Sendo assim, para cada variável dependente são feitas análises de sensibilidade das variáveis independentes pelo SRC e PCC.
Com o intuito de ordenação dos parâmetros mais influentes, tendo em vista que há quatro ambientes a serem analisados na edificação, foi utilizada a média ponderada de cada variável dependente do item "Variáveis dependentes" na análise de sensibilidade, obtendo-se novos coeficientes SRC e PCC.

\section{Análise de variabilidade}

A análise de variabilidade está associada ao intervalo de variação das variáveis dependentes. Os intervalos foram apresentados por meio de histogramas de frequência de ocorrência para a verificação da forma da distribuição de saída.

Esta análise também pode ser interpretada como uma análise de risco, pois, dependendo da concepção do experimento, pode-se apontar as probabilidades de que uma das variáveis dependentes exceda algum valor em determinada população de edificações.

Foram calculados a média e o desvio padrão das distribuições de dados, assumindo-se a normalidade. As probabilidades de ocorrência dos valores foram calculadas conforme a distribuição normal, sendo conhecidos a média e o desvio padrão da amostra.

\section{Análise de simulações individuais}

Esta análise trata de escolher alguns casos que apresentaram valores extremos em cada uma das variáveis dependentes. Foram discutidas as configurações das simulações individuais, de forma a entender as combinações que geraram os piores e os melhores resultados.

\section{Resultados}

\section{Análise de sensibilidade}

A Tabela 2 mostra os coeficientes de sensibilidade SRC e PCC para as simulações, que representam a influência dos parâmetros de entrada nas variáveis dependentes de graus-hora de resfriamento e consumos para aquecimento e refrigeração.

O coeficiente negativo indica que, quando ocorre um aumento do valor do parâmetro, ocorre diminuição na variável dependente. Analogamente, o coeficiente positivo indica que, quando o parâmetro aumenta seu valor, a variável dependente também aumenta.

Os parâmetros mais influentes nos graus-hora de resfriamento da Tabela 2 foram a absortância solar da cobertura $(\alpha c o b)$, a transmitância térmica da cobertura (Ucob) e o contato da cobertura com o exterior (cob), e quanto maiores seus valores, 
maiores os graus-hora de resfriamento. Para o contato da cobertura com o exterior (cob), por ser uma variável discreta, o valor 1 (quando há contato com o exterior) aumenta os graus-hora de resfriamento em comparação com o valor 0 .

Já os parâmetros de capacidade térmica das paredes externas (CTparext), do contato do piso (piso) e a capacidade térmica da cobertura (CTcob) foram os mais influentes nas variações negativas, e quanto maiores seus valores, menores os graushora de resfriamento. $\mathrm{O}$ valor 1 para o contato do piso (quando há contato com o solo) gera menor valor de graus-hora de resfriamento do que o valor 0 (quando o piso não transfere calor).

Os parâmetros mais influentes no consumo relativo com aquecimento da Tabela 2 foram a emissividade da cobertura ( $\varepsilon$ cob), a transmitância térmica das paredes externas (Uparext) e a transmitância térmica da cobertura (Ucob), e quanto maiores seus valores, maior o consumo com aquecimento. Para as variações negativas, os mais influentes são contato do piso (piso), a capacidade térmica das paredes externas (CTparext) e a capacidade térmica da cobertura (CTcob), e quanto maiores seus valores, menor é o consumo com aquecimento.

Os parâmetros mais influentes no consumo relativo com refrigeração da Tabela 2 foram a capacidade térmica da cobertura (CTcob), a absortância solar da cobertura ( $\alpha$ cob) e a absortância solar das paredes externas ( $\alpha$ par) para variações positivas. Para as variações negativas, os mais influentes foram a emissividade da cobertura ( $\varepsilon c o b)$, a transmitância térmica das paredes externas (Uparext) e o contato do piso (piso).

Deve-se ressaltar que a emissividade foi considerada em ambas as superfícies (interna e externa) da cobertura. A manutenção da emissividade baixa da superfície externa da cobertura é uma tarefa difícil na prática, no entanto esse fato foi considerado neste trabalho de forma a avaliar sua influência.

Os métodos SRC e PCC apontaram os mesmos parâmetros influentes na maior parte dos casos. O coeficiente de determinação $\left(\mathrm{R}^{2}\right)$ sempre teve valor acima de 0,70 , indicando boa correlação, mas não excelente, o que indica que há certa não linearidade no modelo proposto. Apenas o consumo com refrigeração do dormitório 1 teve o $\mathrm{R}^{2}$ ligeiramente menor que 0,70 .

A Figura 4 apresenta graficamente as variáveis independentes mais influentes (que apresentaram maior coeficiente PCC e SRC em módulo) em cada uma das variáveis dependentes. As nuvens de dados ilustram bem a amostragem aleatória em uma análise global, pois todos os parâmetros são variados ao mesmo tempo. Mesmo assim, nessas variáveis de alto coeficiente SRC e PCC, percebese claramente a tendência encontrada para aumentar ou diminuir a variável dependente. Percebe-se também a diferença de uma variável contínua (absortância solar da cobertura) com uma variável discreta (emissividade da cobertura).

Ao se ter o conhecimento desses parâmetros mais influentes, pode-se discutir o seguinte:

(a) em estudos de otimização, deve-se dar ênfase aos parâmetros de maiores coeficientes PCC e SRC em módulo da Tabela 2. Já o fator de ventilação, a orientação solar, as propriedades do vidro e as propriedades das paredes internas foram menos influentes que os demais;

(b) em demais estudos de análise de sensibilidade, pode-se excluir os parâmetros que não influenciam muito, de forma a aperfeiçoar o processo de configuração das simulações;

(c) percebe-se a dificuldade de propor estratégias de eficiência energética, uma vez que os parâmetros mais influentes são muito diferentes para cada variável dependente. Por exemplo, uma alta emissividade diminui bastante o consumo de energia com refrigeração noturna, mas aumenta bastante o consumo de energia com aquecimento noturno, e é indiferente em relação aos graus-hora de resfriamento; e

(d) outro exemplo é em relação à absortância solar da cobertura, que é o principal parâmetro nos graus-hora de resfriamento, um dos principais no consumo com refrigeração, mas um valor baixo prejudica o consumo de energia com aquecimento noturno.

No caso do clima de Florianópolis, SC, percebe-se a dificuldade de se proporem soluções de otimização para as estações de verão e inverno e para os períodos diurnos e noturnos do dia. Por não ser objetivo deste trabalho, esse assunto não será discutido com profundidade, mas uma solução possível é a utilização de métodos estatísticos de Teoria Bayesiana (DE WIT; AUGENBROE, 2002; HEO; CHOUDHARY; AUGENBROE, 2012) ou algoritmos genéticos (WANG; XU, 2006; VILLA; LABAYRADE, 2011) que tenham como objetivo encontrar a melhor solução que satisfaça boas condições de graus-hora de resfriamento, consumos de energia com aquecimento e refrigeração simultaneamente. 
Ambiente Construído, Porto Alegre, v. 13, n. 4, p. 135-148, jul./set. 2013.

Tabela 2 - Coeficientes de sensibilidade dos métodos PCC e SRC para as três variáveis dependentes para o arquivo TRY

\begin{tabular}{|c|c|c|c|c|c|c|c|c|c|c|}
\hline \multicolumn{11}{|c|}{ Graus hora de resfriamento } \\
\hline \multirow{2}{*}{$\begin{array}{r}\text { Variável } \\
\text { independente }\end{array}$} & \multicolumn{2}{|c|}{ Sala-cozinha } & \multicolumn{2}{|c|}{ Dormitório 1} & \multicolumn{2}{|c|}{ Dormitório 2} & \multicolumn{2}{|c|}{ Dormitório 3} & \multicolumn{2}{|c|}{ Média } \\
\hline & $\mathrm{PCC}$ & SRC & $\mathrm{PCC}$ & SRC & $\mathrm{PCC}$ & SRC & PCC & SRC & PCC & SRC \\
\hline$a c o b$ & 0,677 & 0,411 & 0,632 & 0,412 & 0,723 & 0,472 & $\$, 662$ & 0,435 & 0,703 & 0,437 \\
\hline Ucob & 0,643 & 0,378 & 0,539 & 0,326 & 0,687 & 0,430 & 0,595 & 0,369 & 0,652 & 0,384 \\
\hline $\mathrm{cob}$ & 658 & 0,387 & 0,545 & 0,326 & 0,298 & 140 & 0,595 & 0,362 & 0,618 & 0,346 \\
\hline apar & 0,576 & 0,315 & 0,585 & 0,366 & 0,588 & 0,329 & 0,415 & 0,226 & 0,593 & 0,327 \\
\hline Uparext & , 464 & 0,235 & 0,434 & 0,245 & 0,450 & 0,228 & 0,286 & 148 & 0,461 & 0,231 \\
\hline Solar & 0,428 & 0,212 & $\phi, 066$ & 6,034 & $-0,181$ & $-0,084$ & 0,470 & 0,264 & 0,302 & 141 \\
\hline Uvid & $-6,015$ & $-6,007$ & 0,003 & 0,002 & $-6,014$ & $-6,006$ & $\phi, 019$ & 0,010 & $-6,005$ & $-0,002$ \\
\hline$a c o b$ & $-0,049$ & $-(0,022$ & $-6,162$ & $-6,083$ & $-6,142$ & $-0,065$ & $-(0,122$ & $-0,061$ & $-6,111$ & $-0,050$ \\
\hline Uparint & $-6,107$ & $-6,048$ & $-6,111$ & $-6,056$ & $-6,055$ & $-6,025$ & $-0,120$ & $-6,060$ & $-6,112$ & $-6,050$ \\
\hline Fvent & $-0,130$ & $-0,058$ & $-0,189$ & $-0,097$ & $-0,210$ & $-0,096$ & $-0,197$ & $-0,098$ & - & $-0,081$ \\
\hline CTparint & $-0,227$ & $-6,103$ & $-0,187$ & $-0,096$ & $-6,264$ & $-6,123$ & $-6,327$ & $-6,170$ & $-0,258$ & $-0,118$ \\
\hline Somb & $-0,215$ & $-0,098$ & $-0,244$ & $-0,127$ & $-0,262$ & $-0,122$ & $-6,332$ & $-0,173$ & $-0,268$ & $-0,123$ \\
\hline CTcob & $-6,380$ & $-6,183$ & $-0,254$ & $-6,132$ & $-0,378$ & $-0,183$ & $-6,295$ & $-6,152$ & $-6,364$ & $-0,172$ \\
\hline piso & $-0,348$ & $-0,166$ & $-6,355$ & $-0,192$ & $-0,422$ & $-0,211$ & $-6,394$ & $-0,211$ & $-0,396$ & $-0,191$ \\
\hline CTparext & $-0,451$ & $-0,225$ & $-0,423$ & $-0,235$ & $-0,476$ & $-0,243$ & $-0,253$ & $-0,128$ & $-0,451$ & $-0,223$ \\
\hline $\mathrm{R}^{2}$ & 0,8 & & 0,7 & & 0,80 & & 0,7 & & 0,82 & \\
\hline \multicolumn{11}{|c|}{ Consumo relativo com aquecimento } \\
\hline Variárel & \multicolumn{2}{|c|}{ Sala-cozinha } & \multicolumn{2}{|c|}{ Dormitório l } & \multicolumn{2}{|c|}{ Dormitório 2} & \multicolumn{2}{|c|}{ Dormitório 3} & \multicolumn{2}{|c|}{ Média } \\
\hline independente & $\mathrm{PCC}$ & SRC & $\mathrm{PCC}$ & SRC & $\mathrm{PCC}$ & SRC & $\mathrm{PCC}$ & SRC & PCC & SRC \\
\hline$a c o b$ &, 691 & 0,437 & $\$, 677$ & 0,395 & 0,777 & 0,497 & 0,638 & 0,422 & 0,706 & 0,445 \\
\hline Uparext & 0,651 & 0,393 & 0,772 & 0,522 & 0,773 & 0,490 & 0,427 & 0,241 & 690 & (0,427 \\
\hline Ucob & 654 & 0,398 & 0,647 & 0,366 & 0,783 & 0,509 &, 653 & 0,441 & (1),684 & 0,422 \\
\hline $\mathrm{cob}$ & 0,712 & 0,460 & 0,700 & 0,416 & 0,122 & 0,049 & 694 & 0,487 & 0,676 & (1,406 \\
\hline Somb & (116 & $\$, 053$ & 0,157 & 0,068 &, 161 & 065 & 150 & $\$, 077$ & (139 &, 062 \\
\hline Fvent & 0,022 & $\$, 010$ & $\$, 053$ & 0,023 & 0,078 & 0,031 & 0,044 & 0,022 & $\$, 040$ & 0,018 \\
\hline Uparint & $-0,047$ & $-0,021$ & $-0,040$ & $-0,017$ & 036 & 0,014 & 0,089 & 0,046 & $-0,017$ & $-0,008$ \\
\hline Solar & $-(0,031$ & $-(2,014$ & $-(0,090$ & $-(0,039$ & 0,192 & 079 & $-(8,121$ & $-(0,062$ & $-8,028$ & $-0,013$ \\
\hline Uvid & $-(0,032$ & $-(2,015$ & $-(0,051$ & $-(0,022$ & $-(2,045$ & $-(0,018$ & $-0,040$ & $-(0,020$ & $-0,040$ & $-(0,018$ \\
\hline CTparint & $-(0,096$ & $-(0,044$ & $-(4,092$ & $-(0,039$ & $-(1), 098$ & $-(0,039$ & $-0,108$ & $-(0,055$ & $-(2), 100$ & $-(0,045$ \\
\hline apar & -171 & $-0,080$ & $-(0,235$ & $-0,104$ & $-(0,264$ & $-0,110$ & $-1,131$ & $-0,067$ & - 197 & $-0,090$ \\
\hline$a c o b$ & -186 & $-(0,087$ & $-(9,222$ & $-(0,097$ & $-(0,305$ & $-8,128$ & $-19,197$ & $-(0,102$ & -217 & $-0,099$ \\
\hline CTcob & $-(1), 349$ & $-(0,169$ & $-(0,319$ & $-(0,144$ & $-(0,406$ & $-(0,178$ & $-0,275$ & $-0,145$ & $-(9,350$ & $-0,166$ \\
\hline CTparext & $-0,384$ & $-0,189$ & $-0,433$ & $-(0,205$ & $-4,423$ & $-8,186$ & $-0,142$ & $-0,072$ & $-(0,380$ & $-0,182$ \\
\hline piso & $-(0,377$ & $-(0,186$ & $-(0,370$ & $-(0,170$ & $-(0,463$ & $-(0,210$ & $-(0,350$ & $-(0,190$ & $-(0,393$ & $-(0,191$ \\
\hline $\mathrm{R}^{2}$ & 0,7 & & 0,8 & & 0,8 & & 0,7 & & 0,80 & \\
\hline \multicolumn{11}{|c|}{ Consumo relativo com refrigeração } \\
\hline Variável & \multicolumn{2}{|c|}{ Sala-cozinha } & Dormi & ório 1 & Dormi & rio 2 & Dormi & rio 3 & Mé & \\
\hline independente & $\mathrm{PCC}$ & SRC & $\mathrm{PCC}$ & SRC & $\mathrm{PCC}$ & SRC & $\mathrm{PCC}$ & SRC & PCC & SRC \\
\hline CTcob & $0, \frac{1}{4} 69$ & $0, \frac{1}{2} 91$ & 0,414 & $0, \frac{2}{253}$ & $0, \frac{1}{1} 16$ & $0, \frac{2}{287}$ & $0, \frac{4}{4} 03$ & 0,241 & $0, \frac{4}{19} 92$ & $0, \frac{1}{2} 80$ \\
\hline$a c o b$ & $0, \frac{3}{1} 55$ & $0, \frac{1}{209}$ & $0, \frac{140}{4}$ & $0, \frac{1}{2} 74$ & 0,02 & $0, \frac{2}{2} 77$ & 0,470 & $0, \frac{192}{1}$ & $0, \frac{4}{4} 92$ & $0, \frac{2}{2} 81$ \\
\hline apar & 0,336 & 0,197 & 0,476 & 0,303 & 0,447 & $0, \frac{2}{2} 39$ & 0,351 & 0,206 & 0,455 & 0,255 \\
\hline CTparext & 0,418 & $0, \frac{1}{2} 52$ & 0,411 & 0,251 & 0,405 & 0,211 & 0,186 & 0,103 & 0,397 & 0,214 \\
\hline CTparint & 0,119 & 0,066 & 0,182 & 0,103 & 0,226 & 0,110 & 0,321 & 0,185 & 0,245 & 0,125 \\
\hline Solar & 0,189 & 0,106 & 0,450 & 0,028 & $-0,502$ & $-0,152$ & 0,376 & 0,223 & 0,108 & 0,054 \\
\hline Uparint & 0,0 & 0,028 & 0,095 & 0,033 & 0,081 & 0,039 & $-0,008$ & $-0,004$ & 0,050 & 0,025 \\
\hline Uvid & 0,007 & 0,004 & 0,015 & 0,008 & 0,011 & 0,805 & 0,030 & 0,016 & 0,019 & 0,009 \\
\hline Fvent & $-0,005$ & $-0,003$ & $-0,80$ & $-0,039$ & $-0,039$ & $-0,0$ & $-0,855$ & $-0,030$ & $-0,0,52$ & $-0,826$ \\
\hline Somb & $-0,112$ & $-0,462$ & $-0,198$ & $-0,112$ & $-0,124$ & $-0,859$ & $-0, \frac{2}{1} 39$ & $-0, \frac{1}{1} 34$ & $-0,199$ & $-0,100$ \\
\hline $\mathrm{cob}$ & $-0, \frac{1}{1} 76$ & $-0,157$ & $-0,17$ & $-0,123$ & 0,840 & 0,019 & $-0, \frac{1}{1} 58$ & $-0,145$ & $-0,12$ & $-0,107$ \\
\hline Ucob & $-0,323$ & $-0,190$ & $-0,42$ & $-0, \frac{1}{1} 41$ & $-0,419$ & $-0,23$ & $-0,332$ & $-0,194$ & $-0,361$ & $-0,195$ \\
\hline piso & $-0,300$ & $-0,173$ & $-0,340$ & $-0,02$ & $-0,342$ & $-0,174$ & $-0,348$ & $-0,04$ & $-0,374$ & $-0,01$ \\
\hline Uparext & $-0,423$ & $-0, \frac{1}{1} 58$ & $-0,424$ & $-0, \frac{1}{1} 62$ & $-0,450$ & $-0,42$ & $-0,245$ & $-0,139$ & $-0,428$ & $-0, \frac{1}{3} 37$ \\
\hline$\varepsilon c o b$ & $-0,306$ & $-0, \frac{1}{1} 51$ & $-0,568$ & $-0,3,02$ & $-0,784$ & $-0,605$ & $-0,591$ & $-0,325$ & $-0,754$ & $-0,5,73$ \\
\hline $\mathrm{R}^{\mathrm{a}}$ & 0,7 & & 0,6 & & 0,7 & & 0,7 & & 0,76 & \\
\hline
\end{tabular}

144 Silva, A. S.; Ghisi, E. 
Figura 4 - Variáveis independentes mais influentes em módulo no GHR, CA e CR do arquivo TRY

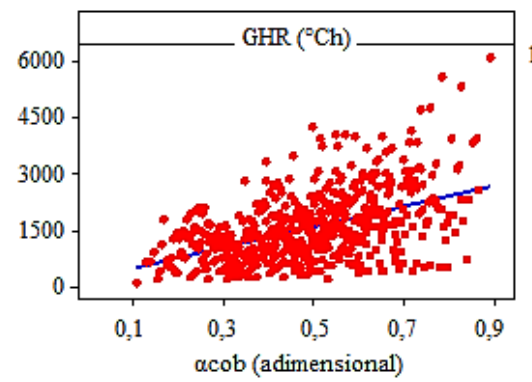

\section{Variabilidade dos dados}

A Figura 5 apresenta a variabilidade das variáveis dependentes para o arquivo TRY. Foram utilizados os valores médios dos ambientes.

No caso dos graus-hora de resfriamento da Figura 5a, a média dos dados é de $1.577^{\circ} \mathrm{Ch}$, e os valores individuais variam de 75 a $6.085^{\circ} \mathrm{Ch}$. A partir dos $4.100^{\circ} \mathrm{Ch}$ a probabilidade de ocorrência é mínima. Isso aponta que há certas combinações de parâmetros que geram desempenho muito pior do que os demais, porém têm pouca probabilidade de ocorrência.

No caso do consumo com aquecimento da Figura $5 \mathrm{~b}$, a média é de $39,23 \mathrm{kWh} / \mathrm{m}^{2}$.ano, enquanto para o consumo com refrigeração da Figura 5c a média é de $13,76 \mathrm{kWh} / \mathrm{m}^{2}$.ano. Isso indica que o consumo de energia com aquecimento para o clima de Florianópolis é significativamente maior do que para refrigeração, no caso da edificação residencial analisada.

Apesar de não reportada graficamente, foi notada grande diferença do consumo de energia com refrigeração das salas em relação aos dormitórios. Enquanto a sala consome $3,35 \mathrm{kWh} / \mathrm{m}^{2}$.ano na média da amostra, os dormitórios consomem de 21,40 a $29,01 \mathrm{kWh} / \mathrm{m}^{2}$.ano. Tal fato não é observado nos graus-hora de resfriamento, nem no consumo com aquecimento.

\section{Análise de simulações individuais}

A Tabela 3 mostra os casos extremos encontrados para as três variáveis dependentes, para as simulações com o arquivo TRY. A Tabela 4 apresenta as configurações dos parâmetros para os casos extremos.

Da análise das Tabelas 3 e 4 conclui-se que, para os graus-hora de resfriamento, o que diferenciou os dois casos extremos foi a absortância solar da cobertura e das paredes externas, o contato da cobertura com o exterior, o contato do piso e a transmitância térmica das paredes externas. Os demais parâmetros se mostraram invariáveis.

Para o consumo relativo com refrigeração, também foi notada a importância da absortância solar da cobertura, a emissividade da cobertura, o contato do piso e o sombreamento das aberturas.

Para o consumo com aquecimento, foi notada a influência da emissividade da cobertura, das absortâncias solares, da transmitância das paredes internas e externas, e da capacidade térmica das paredes externas, o contato da cobertura com o exterior e o contato do piso.

Algumas constatações gerais podem ser apontadas:

(a) a emissividade da cobertura influencia muito nos consumos de energia. Quando é baixa, o consumo com aquecimento é alto; quando é alta, o consumo com refrigeração é alto. Ambos os fatos competem entre si. A emissividade não foi muito influente nos graus-hora de resfriamento, ante os outros parâmetros;

(b) o contato com o piso influencia muito em todos os casos, e o contato com o solo mostrou-se a melhor opção. A falta da transferência de calor (piso=0) gerou o pior resultado no consumo com refrigeração. Já o contato com o exterior por pilotis gerou os piores resultados com aquecimento e resfriamento;

(c) o contato da cobertura com o exterior gerou os piores resultados para resfriamento e aquecimento. A falta de transferência de calor da cobertura $(\mathrm{cob}=0)$ gerou os melhores resultados. No entanto, é impossível de ser alcançada na prática em uma habitação unifamiliar. Sendo assim, gerou os melhores resultados apenas para os fins deste trabalho, e seriam aplicáveis apenas a habitações multifamiliares de dois ou mais pavimentos;

(d) o caso ID 479 quase elimina os graus-hora de resfriamento $\left(75^{\circ} \mathrm{Ch}\right)$, enquanto a média da distribuição é de $1.577^{\circ} \mathrm{Ch}$ (Figura 5a), sendo a melhor opção nos períodos quentes encontrada. 
Figura 5 - Análise de variabilidade dos valores médios de GHR, CA e CR para o arquivo TRY
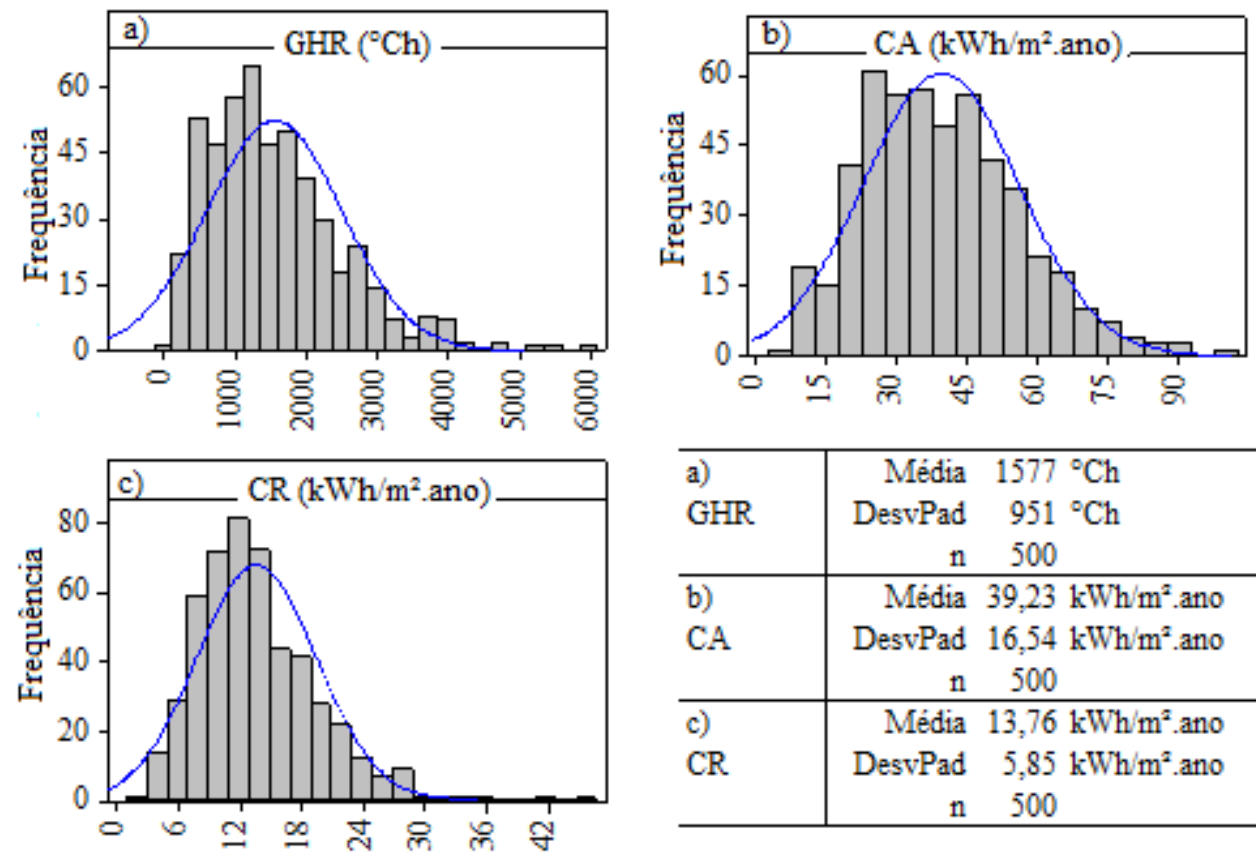

\begin{tabular}{l|rl}
\hline a) & Média & $1577^{\circ} \mathrm{Ch}$ \\
GHR & DesvPad $951^{\circ} \mathrm{Ch}$ \\
& $\mathrm{n} \quad 500$ \\
\hline b) & Média $39,23 \mathrm{kWh} / \mathrm{m}^{2}$.ano \\
CA & DesvPad $16,54 \mathrm{kWh} / \mathrm{m}^{2}$.ano \\
& $\mathrm{n} \quad 500$ \\
\hline c) & Média $13,76 \mathrm{kWh} / \mathrm{m}^{2}$.ano \\
CR & DesvPad $5,85 \mathrm{kWh} / \mathrm{m}^{2}$.ano \\
& $\mathrm{n} \quad 500$ \\
\hline
\end{tabular}

Tabela 3 - Valores extremos mínimos e máximos para as três variáveis dependentes e para os casos com arquivo TMY e com TRY

\begin{tabular}{cc|ccc}
\hline ID & Variável & $\begin{array}{c}\mathrm{GHR} \\
\left({ }^{\circ} \mathrm{Ch}\right)\end{array}$ & $\begin{array}{c}\mathrm{CA} \\
\left(\mathrm{kWh} / \mathrm{m}^{2} \text {.ano }\right)\end{array}$ & $\begin{array}{c}\mathrm{CR} \\
\left(\mathrm{kWh} / \mathrm{m}^{2} \text {.ano }\right)\end{array}$ \\
\hline 479 & GHRmín & $\mathbf{7 5}$ & 14,99 & 13,24 \\
281 & GHRmáx & $\mathbf{6 0 8 6}$ & 83,81 & 12,13 \\
357 & CAmín & 542 & $\mathbf{6 , 7 2}$ & 23,63 \\
284 & CAmáx & 880 & $\mathbf{9 8 , 5 1}$ & 3,13 \\
38 & CRmín & 2079 & 60,86 & $\mathbf{4 , 4 4}$ \\
434 & CRmáx & 5586 & 17,80 & $\mathbf{4 5 , 6 0}$ \\
\hline
\end{tabular}

Tabela 4 - Configurações dos parâmetros termofísicos para os casos extremos da Tabela 3

\begin{tabular}{|c|c|c|c|c|c|c|c|c|c|c|c|c|c|c|c|}
\hline ID & $\begin{array}{l}\text { Ucob } \\
\left(\mathrm{W} / \mathrm{m}^{2} . \mathrm{K}\right)\end{array}$ & $\begin{array}{l}\text { CTcob } \\
\left(\mathrm{kJ} / \mathrm{m}^{2} . \mathrm{K}\right)\end{array}$ & $\begin{array}{l}\alpha c o b \\
(\mathrm{adm})\end{array}$ & $\begin{array}{l}\varepsilon c o b \\
(\mathrm{adm})\end{array}$ & $\begin{array}{l}\text { Uparext } \\
\left(\mathrm{W} / \mathrm{m}^{2} . \mathrm{K}\right)\end{array}$ & $\begin{array}{l}\text { CTparext } \\
\left(\mathrm{kJ} / \mathrm{m}^{2} . \mathrm{K}\right)\end{array}$ & $\begin{array}{l}\text { Uparint } \\
\left(\mathrm{W} / \mathrm{m}^{2} . \mathrm{K}\right)\end{array}$ & $\begin{array}{l}\text { CTparint } \\
\left(\mathrm{kJ} / \mathrm{m}^{2} . \mathrm{K}\right)\end{array}$ & $\begin{array}{l}\alpha p a r \\
(\mathrm{adm})\end{array}$ & $\begin{array}{l}\text { cob } \\
(\mathrm{adm})\end{array}$ & $\begin{array}{l}\text { piso } \\
(\mathrm{adm})\end{array}$ & $\begin{array}{l}\text { Fvent } \\
(\text { adm })\end{array}$ & $\begin{array}{l}\text { Somb } \\
(\mathrm{adm})\end{array}$ & $\begin{array}{l}\text { Solar } \\
\text { (graus) }\end{array}$ & $\begin{array}{l}\text { Uvid } \\
\left(\mathrm{W} / \mathrm{m}^{2} . \mathrm{K}\right)\end{array}$ \\
\hline 479 & 2,5 & 200 & 0,11 & 0,9 & 1,00 & 150,0 & 2,35 & 150 & 0,23 & 0 & 1,0 & 0,51 & 1 & 1 & 6,27 \\
\hline 281 & 4,0 & 20 & 0,89 & 0,9 & 3,70 & 150,0 & 2,35 & 150 & 0,73 & 1 & 0,5 & 0,54 & 1 & 1 & 6,27 \\
\hline 357 & 2,5 & 110 & 0,76 & 0,1 & 1,00 & 250,1 & 1,00 & 150 & 0,81 & 0 & 1,0 & 0,46 & 1 & 3 & 6,27 \\
\hline 284 & 4,0 & 110 & 0,21 & 0,9 & 2,35 & 49,9 & 3,70 & 150 & 0,36 & 1 & 0,5 & 0,64 & 1 & 2 & 6,27 \\
\hline 38 & 2,5 & 20 & 0,53 & 0,9 & 2,35 & 49,9 & 2,35 & 49,9 & 0,25 & 1 & 0,5 & 0,79 & 1 & 3 & 6,27 \\
\hline 434 & 4,0 & 200 & 0,79 & 0,1 & 2,35 & 150,0 & 3,70 & 49,9 & 0,60 & 1 & 0,0 & 0,56 & 0 & 2 & 6,27 \\
\hline
\end{tabular}

\section{Conclusões}

Este estudo apresentou uma análise de sensibilidade global dos parâmetros relacionados ao desempenho térmico e eficiência energética de uma edificação residencial, configurado conforme o método de simulação do RTQ-R.

Foram obtidos os parâmetros que mais influenciam nos graus-hora de resfriamento, no consumo relativo com aquecimento e com refrigeração. Os parâmetros em destaque são a absortância solar da cobertura e a emissividade da cobertura.

A eficácia dos métodos SRC e PCC utilizados está ligada ao coeficiente de determinação $\mathrm{R}^{2}$, que conseguiu explicar a maior parte da variância da amostra linearmente, sendo superior a 0,70 em praticamente todos os casos.

Este estudo contribui na elaboração de métodos de otimização do desempenho térmico e energético das edificações, para que os esforços e investimentos possam ser feitos nos parâmetros 
realmente mais influentes. Também foram apontados alguns parâmetros que precisam de atenção em todas as variáveis dependentes, e alguns que são influentes apenas em uma ou outra variável dependente.

Há uma problemática na análise dos parâmetros menos influentes, pois são diferentes dependendo da variável analisada, que gera indecisão quanto à proposição de soluções de desempenho para os períodos de verão e inverno simultaneamente. Esse fato é importante e deve ser mais bem analisado em estudos globais de otimização do desempenho, e o método apresentado neste trabalho tem aplicabilidade.

Essa problemática interfere nas recomendações projetuais de normas e certificações, uma vez que, para um mesmo clima analisado, certa combinação de parâmetros gera bons resultados em determinada estação do ano, enquanto pode gerar piores condições em outras estações. Tendo em vista que as recomendações projetuais são geralmente estáticas (ou seja, que não podem variar significativamente de magnitude depois da construção), seria difícil conseguir uma combinação de parâmetros que resulte em baixos valores para os graus-hora e para os consumos de energia com aquecimento simultaneamente. Os métodos de otimização poderiam conciliar as três variáveis dependentes e encontrar uma combinação de parâmetros que satisfaça condições menos rigorosas, mas não as ideais para essas variáveis.

A análise de variabilidade dos parâmetros é interessante para a proposta de normalizações e regulamentos de eficiência energética de edificações, pois se podem determinar intervalos probabilísticos para os resultados. Tendo em vista que o nível de classificação do RTQ-R varia de "A" (mais eficiente) a "E" (menos eficiente), a análise de variabilidade deste trabalho pode ajudar a propor amplitudes diferentes para os intervalos dos níveis de eficiência. Uma alternativa seria a divisão dos níveis com base na área abaixo das curvas de densidade de probabilidade da Figura 5. Isso ajudaria na classificação das edificações e tornaria a análise mais justa, pois um valor discrepante considerado na simulação não iria prejudicar a análise por ser de baixa probabilidade de ocorrência.

Estudos mais completos serão realizados com este mesmo método apresentado, abrangendo diferentes tipologias construtivas habitacionais e diferentes climas do Brasil.

\section{Referências}

BREESCH, H.; JANSSENS, A. Building

Simulation to Predict the Performances of Natural

Night Ventilation: uncertainty and sensitivity analysis. In: INTERNATIONAL IBPSA

CONFERENCE, 9., Montréal, 2005.

Proceedings... Montréal, 2005

BREESCH, H.; JANSSENS, A. Performance Evaluation of Passive Cooling in Office Buildings Based on Uncertainty and Sensitivity Analysis. Solar Energy, v. 84, n. 8, p. 1453-1467, 2010.

DE WIT, S.; AUGENBROE, G. Analysis of Uncertainty in Building Design Evaluations and Its Implications. Energy and Buildings, v. 34, n. 9, p. 951-958, 2002.

GOULART, S.; LAMBERTS, R.; FIRMINO, S. Dados Climáticos Para Projeto e Avaliação Energética de Edificações Para 14 Cidades Brasileiras. Florianópolis: Núcleo de Pesquisa em Construção, UFSC, 1998. 345 p.

HEISELBERG, P. et al. Application of Sensitivity Analysis in Design of Sustainable Buildings. Renewable Energy, v. 34, n. 9, p. 2030-2036, 2009.

HEO, Y., CHOUDHARY, R.; AUGENBROE, G. A. Calibration of Building Energy Models For Retrofit Analysis Under Uncertainty. Energy and Buildings, v. 47, n. 4, p. 550-560, 2012.

HOPFE, C. J.; HENSEN, J. L. M. Uncertainty Analysis in Building Performance Simulation For Design Support. Energy and Buildings, v. 43, n. 10, p. 2798-2805, 2011.

HYUN, S.; PARK, C.; AUGENBROE, G. Uncertainty and Sensitivity Analysis of Natural Ventilation in High-Rise Apartment Buildings. In: BUILDING SIMULATION, China, 2007.

Proceedings... China, 2007.

INSTITUTO NACIONAL DE METROLOGIA, QUALIDADE E TECNOLOGIA. Regulamento Técnico da Qualidade Para o Nível de Eficiência Energética Edificações Residenciais. RTQ-R. Portaria n.18, de 16 de Janeiro de 2012. INMETRO, 2012.

KLEIJNEN, J. P. Sensitivity Analysis and Related Analyses: a review of some statistical techniques. Statistic and Computing Simulation, v. 57, n. 1/4, p. 111-142, 1997.

MACDONALD, I.; STRACHAN, P. Practical Application of Uncertainty Analysis. Energy and Buildings, v. 33, n. 3, p. 219-227, 2001. 
MARA, T. A.; TARANTOLA, S. Application of Global Sensitivity Analysis of Model Output to Building Thermal Simulations. Building Simulation, v. 1, n. 4, p. 290-302, 2008.

MECHRI, H. E.; CAPOZZOLI, A.; CORRADO, V. Use of the ANOVA Approach For Sensitive Building Energy Design. Applied Energy, v. 87, n. 10, p. 3073-3083, 2010.

MENDES, N. et al. Uso de Instrumentos Computacionais Para Análise do Desempenho Térmico e Energético de Edificações no Brasil. Ambiente Construído, Porto Alegre, v. 5, n. 4, p. 47-68, out./dez. 2005.

MORRIS, M. D. Factorial Sampling Plans For Preliminary Computational Experiments.

Technometrics, v. 33, n. 2, p. 161-174, 1991.

RYAN, E. M.; SANQUIST, T. F. Validation of Building Energy Modeling Tools Under Idealized and Realistic Conditions. Energy and Buildings, v. 47, p. 375-382, apr. 2012.

SALTELLI, A.; TARANTOLA, S.;

CAMPOLONGO, F. Sensitivity Analysis as an Ingredient of Modeling. Statistical Science, v. 15, n. 4, p. 377-395, 2000.

SIMLAB. Simlab 2.2: reference manual. Simulation Environment for Uncertainty and Sensitivity Analysis. Disponível em:

<http://ipsc.jrc.ec.europa.eu/?id=753>. Acesso em: 15 mar. 2013.

SOBOL', I. M. Sensitivity Analysis For Nonlinear Mathematical Models. Mathematical Modelling and Computational Experiment, v. 1, p. 407414, 1993.
SORGATO, M. J.; LABMERTS, R. Análise de Sensibilidade dos Parâmetros Utilizados Para a Simulação Computacional de Ventilação Natural, no Desempenho Térmico de Uma Edificação Residencial Unifamiliar. In: ENCONTRO NACIONAL DE TECNOLOGIA DO AMBIENTE CONSTRUÍDO, Juiz de Fora, 2012. Anais... Juiz de Fora: ANTAC, 2012.

TIAN, W. A Review of Sensitivity Analysis Methods in Building Energy Analysis. Renewable and Sustainable Energy Reviews, v. 20, p. 411419, 2013.

VAN DER KNAAP, A. N. Building Performance Simulation to Support Building Energy

Regulation: a case study for residential buildings in Brazil. Eindhoven, 2011. Thesis - Master Building Services, Department of the Built Environment, Technische Universiteit Eindhoven, Eindhoven, 2011.

VILLA, C.; LABAYRADE, R. 2011. Energy Efficiency vs Subjective Comfort: a multiobjective optimisation method under uncertainty. In: BUILDING SIMULATION, Australia, 2011. Proceedings... Australia, 2011.

WANG, S.; XU, X. Parameter Estimation of Internal Thermal Mass of Building Dynamic Models Using Genetic Algorithm. Energy Conversion and Management, v. 47, n. 13/14, p. 1927-1941, 2006.

YILDIZ, Y.; ARSAN, Z. D. Identification of the Building Parameters That Influence Heating and Cooling Energy Loads For Apartment Buildings in Hot-Humid Climates. Energy, v. 36, n. 7, p. 4287 4296, 2011.

\section{Agradecimentos}

Os autores agradecem ao CNPq pela bolsa de estudos, e à FINEP pelo financiamento do projeto do qual este estudo foi originado.

Arthur Santos Silva

Laboratório de Eficiência Energética em Edificações, Departamento de Engenharia Civil | Universidade Federal de Santa Catarina | Caixa Postal 476 | Florianópolis - SC - Brasil | CEP 88040-900 | Tel.: (48) 3721-5185 | E-mail: arthurssilva07@gmail.com

Enedir Ghisi

Laboratório de Eficiência Energética em Edificações, Departamento de Engenharia Civil | Universidade Federal de Santa Catarina | Email: enedir@labeee.ufsc.br

Revista Ambiente Construído

Associação Nacional de Tecnologia do Ambiente Construído

Av. Osvaldo Aranha, $99-3^{\circ}$ andar, Centro

Porto Alegre - RS - Brasil

CEP $90035-190$

Telefone: +55 (51) 3308-4084

Fax: +55 (51) 3308-4054

www.seer.ufrgs.br/ambienteconstruido

E-mail: ambienteconstruido@ufrgs.br

148 Silva, A. S.; Ghisi, E. 